\title{
GC-MS Analysis of Methanolic Extract of Leaves of Rosmarinus officinalis $\mathbf{L}$.
}

\author{
Mohmmad Ashaq Sofi ${ }^{1, *}$, Anima Nanda ${ }^{1}$, Mohd Abass Sofi ${ }^{2}$, B.K. Nayak ${ }^{3}$ \\ 1 Department of Biomedical Engineering Sathyabama Institute of Science and Technology, Chennai- 600119 \\ 2 Department of Chemistry, Sathyabama Institute of Science and Technology, Chennai- 600119 \\ 3 Department of Botany, K. M. Govt. Institute for Postgraduate Studies and Research (Autonomous), Puducherry-605008 \\ * Correspondence: sofiashaq11@gmail.com; \\ $\dagger$ Presented at International Conference on Bioengineering for Health and Environment (ICBHE 2020)
}

Received: 5.07.2020; Revised: 10.07.2020; Accepted: 12.07.2020; Published: 15.07.2020

\begin{abstract}
Currently, medicinal plants are gaining importance in pharmaceutical and scientific communities. Medicinal plants are the richest natural source of valuable phytochemicals, which can be very useful to treat human diseases and their dysfunctions. Rosmarinus officinalis L. is an important medicinal shrub that belongs to family Lamiaceae and is native to the Mediterranean region. During the present work, an investigation on the photochemical profiling of Rosmarinus officinalis leaves was done. The extraction was made by maceration using methanol as a solvent, and the dried crude extract was analyzed by GC-MS analyzer. Twenty-six compounds were observed from the leaf extracts and found that they have great significance in pharmaceutical science for therapeutically efficient formulations in order to combat various diseases.
\end{abstract}

Keywords: Bioactive compounds; Rosmarinus officinalis; GC-MS analysis; Phytochemical profiling.

(C) 2020 by the authors. This article is an open-access article distributed under the terms and conditions of the Creative Commons Attribution (CC BY) license (https://creativecommons.org/licenses/by/4.0/).

\section{Funding}

This research received no external funding.

\section{Acknowledgments}

This research has no acknowledgment.

\section{Conflicts of Interest}

The authors declare no conflict of interest. 